\section{Semantic Differential Judgments of Cooperators, Competitors and Individualists at Zero- Acquaintance}

\author{
Gregory P. Shelley1,*, Madeleine Page², \\ David M. Kuhlman ${ }^{3}$ \\ ${ }^{1}$ Department of Psychology, Kutztown University of Pennsylvania, \\ Kutztown Pennsylvania, USA, 19530 \\ ${ }^{2,3}$ Department of Psychology, University of Delaware, Newark \\ Delaware, USA, 19711. \\ *Author for correspondence shelley@kutztown.edu.
}

Students rated videotapes of Cooperative $(\mathrm{J})$, Individualistic $(\mathrm{O})$ and Competitive $(\mathrm{R})$ targets describing their previous day. Some ratings represented the Evaluation dimension of social meaning, and others represented Dynamism. As predicted Js were rated more positively than Non-Js on all scales. This suggests a general positivity in cooperators' nonverbal behavior. However, the discussion cites recent research showing that in some contexts cooperator detection may be based on negative nonverbal displays.

\section{Keywords}

cooperator detection, social value orientation, social and personal desirability

\section{Introduction}

Since the classic paper of Messick and McClintock (1968), individual differences in "social value orientation" (SVO) has become increasingly important in social interdependence research and theory. These authors defined five SVOs in terms of concern for one's own well-being and for the well-being of others. Altruism is defined as indifference to self ( $\mathrm{SfO}$ ) and positive concern for other (Ot+), or as Sf0,Ot+. The remaining SVOs are: Cooperation, $(\mathrm{Sf}+, \mathrm{Ot}+)$ Individualism $(\mathrm{Sf}+, \mathrm{Ot0})$, Competition ( $\mathrm{Sf}+, \mathrm{Ot}-)$ and Aggression ( $\mathrm{SfO}, \mathrm{Ot}-$ ). Much subsequent research shows that Altruism and Aggression are rare, so most SVO investigators focus on Cooperators (known as Js), Individualists (Os), and Competitors ( $\mathrm{Rs}_{\mathrm{s}}$.

Messick and McClintock also provided an SVO assessment technique called the "decomposed game" (see Table 1). Standard instructions ask participant to choose between alternatives differing in the points provided to the participants, and to some "other" person with whom the participant has been randomly paired. Participants are asked to imagine that the points have value to both persons, and are told to make what they consider to be the best choice on each of a series of games. For the game in Table 1, Individualists (Os), Competitors $(\mathrm{Rs})$ and Cooperators $\left(\mathrm{Js}_{\mathrm{s}}\right)$ would choose A, B and C respectively. Although there are a variety of ways decomposed games are used (Kuhlman \& Wimberley, 1976; Liebrand \& McClintock, 1988, Van Lange \& Kuhlman, 1994) results consistently show that Js tend to be the most common group followed by Os and then by Rs.

Research on SVO demonstrates temporal stability (Kuhlman, Camac, \& Cunha, 1986) and construct validity, including its relationship to behavior in experimental games (Kuhlman \& Marshello, 1975), person perception (Van Lange \& Kuhlman, 1994), and helping behavior (McClintock \& Allison, 1988).

Relevant to the present paper is work by Shelley, Page, Rives, Yeagley, and Kuhlman (2009) demostrating that SVO is detectable at zero acquaintance based on silent videotapes of $\mathrm{J}_{\mathrm{s}}$, Os and $\mathrm{R}_{\mathrm{s}}$ talking about the previous day. That work adds to increasing evidence that cooperators are detectable at zero acquaintance (Frank, 1988), and that nonverbal behavior plays a role (e.g., Brown, Palameta, \& Moore, 2003; Takagishi, Yamagishi, Tanida, Kiyonari, \& Kanazawa, 2006; Verplaetse, Vaneste, \& Braeckman, 2007).

Cooperator detection is important to theorists concerned with the evolution of cooperation (Dawkins, 1989; Frank, 1988), and so it is appropriate that most studies in this area focus on judgments of cooperative predispositions. In the present paper however, we are concerned with judgments on a variety of traits that previous research suggests should differ as a function of SVO.

Our study is based on findings of an unpublished master's thesis by Paul Teta (1992). Teta's participants rated three hypothetical, "idealized" personality types (Js, Os, and $\mathrm{Rs}_{\mathrm{s}}$ ) on semantic differential scales corresponding to the Evaluation (good/bad) and Dynamism (strong/weak) dimensions of social meaning (Osgood, Suci, \& Tannenbaum, 1957). The hypothetical J was rated higher on both of these dimensions than idealized NonJs. Thus, the a-priori' theories (stereotypes) of SVO appears to be that cooperators are both more "good" or socially desirable, and more "strong" or personally desirable than noncooperators.

The prediction tested here follows from two assumptions, combined with Teta's empirical results. First, we assume that lay-persons' a-priori' theories concerning SVO are correct. This 
Table 1. Example of a Three Choice Decomposed Game

\begin{tabular}{cccc}
\hline & $\mathrm{A}$ & $\mathrm{B}$ & $\mathrm{C}$ \\
\hline You get & 750 & 700 & 700 \\
Other gets & 550 & 400 & 700 \\
\hline
\end{tabular}

Note: "A" maximizes Individualism, "B" Competition, and "C" $\mathrm{Co}$ operation.

is a strong assumption for which there is some empirical support. Specifically, Bem and Lord's (1979) "template matching" research showed that judges' beliefs concerning the real-world behavior of hypothetical $\mathrm{Js}_{\mathrm{s}}$ Os and Rs were reliably associated with an independent group of roommates' descriptions of the real-world behaviors of actual $\mathrm{Js}$, Os and Rs.

Our second assumption is that at least some of the semantic-differential characteristics differentiating $\mathrm{Js}_{\mathrm{s}}, \mathrm{Os}_{\mathrm{s}}$, and $\mathrm{Rs}$, are encoded nonverbally. Thus, we predict that the silent videotapes of Js talking about their previous day will be rated higher than NonJs on semanticdifferential scales loading on the dimensions of Evaluation, and also on Dynamism.

\section{Methods}

\section{Generation of Video Tapes}

In the fall semester introductory psychology students made choices in a set of nine three-choice decomposed games, like those shown in Table 1. Instructions requested students to imagine that the points had value to themselves and the "other person", and that they were to make what they considered to be the best choice in each game. Students who made all nine choices of the Joint (or Own, or Relative) gain choices were classified as $\mathrm{J}_{\mathrm{S}}$, (or Os or Rs), and from this subset students were randomly chosen (with the constraint that the number of male and female $\mathrm{J}_{\mathrm{s}}$, Os and $\mathrm{Rs}_{\mathrm{s}}$ be equal) for a subsequent video-taping study.

Several weeks later these students reported (one at a time) to the laboratory where they were asked by the experimenter (Greg Shelley) who was blind with respect to the student's SVO, to describe what they had done on the previous day from the time they awoke until they went to bed. These stories were videotaped with the students' knowledge. Taping continued until five students of each sex and SVO had given permission to use their videotapes in subsequent research.

Next, the tapes were edited down to thirtysecond video segments in which the student was continually talking. These segments were taken from a point as close as possible to the middle of the story.

\section{Semantic Differential Judgments of the Videotapes}

In the following spring semester one hundred nineteen introductory psychology students (44 males, 75 females) were run in separate groups of approximately 15 . Several weeks prior to this study all participants had completed the decomposed game measure of SVO. Only those students who showed a consistent preference of $\mathrm{J}, \mathrm{O}$, or $\mathrm{R}$ choices were selected for this study.

Instructions made no mention of SVO, or other aspects of social interdependence. Students were simply asked to rate each silent videotape on the nine semantic differential scales described below. Half of the participants saw the segments in one randomized order; for the other participants, the order was reversed.

Five ratings were chosen based on their anticipated loading on the Evaluation factor: (1) Kind/Cruel, (2) Unfair/Fair, (3) Selfish/ Unselfish, (4) Happy/Unhappy and (5) Cooperative/ Uncooperative. The other four had anticipated loadings on the Dynamism factor: (1) Weak/Strong, (2) Dominant/Submissive, (3) Angry/Not Angry and (4) Uncompetitive/Competitive.

Although including both "Cooperative/ Uncooperative" and "Uncompetitive/Competitive" appears redundant, we anticipated that each would provide independent information regarding SVO. Specifically, we have repeatedly found that "cooperative" and "competitive" are not used by our population of American English speakers as semantic opposites. Rather, each loads on a different dimension of social meaning: "cooperative" with Evaluation, and "competitive" with Dynamism. Thus, it is possible for $\mathrm{J}$ (compared to NonJ) targets to receive higher ratings on both cooperative (good) and competitive (strong). Indeed, that is what we predict.

\section{Results}

The factor structure and anticipated loadings for the nine semantic-differential items was well confirmed. Three separate Principal Components Analyses run on J, O and R targets yielded two factors corresponding perfectly to the dimensions of Evaluation and Dynamism. Analyses of the factor scores yielded results very similar to those reported below for the separate items.

Each judge rated a total of thirty videos: five Male Js, five Males Os, and so on. The five ratings within each Target Sex by Target SVO category were averaged for each judge, producing a set of six scores for each of the nine semantic-differential items. These scores were submitted to a doubly multivariate analysis of variance in a 3 (target SVO) by 2 (target sex) by 3 (judge SVO) by 2 (judge sex) by 2 (tape order) design, in which the first two factors are repeated measures.

Since there were no main or interaction multivariate effects for the between judge factors, the remainder of this section is focused on the within-subject, target factors.

\section{Main Effect for Target Sex}

The multivariate test for target sex was significant, $\mathrm{F}(9,104)=16.49, \mathrm{p}<.00001$. With the exception of the Selfish/Unselfish scale, all univariate effects were significant at $p<.001$. Females were rated 


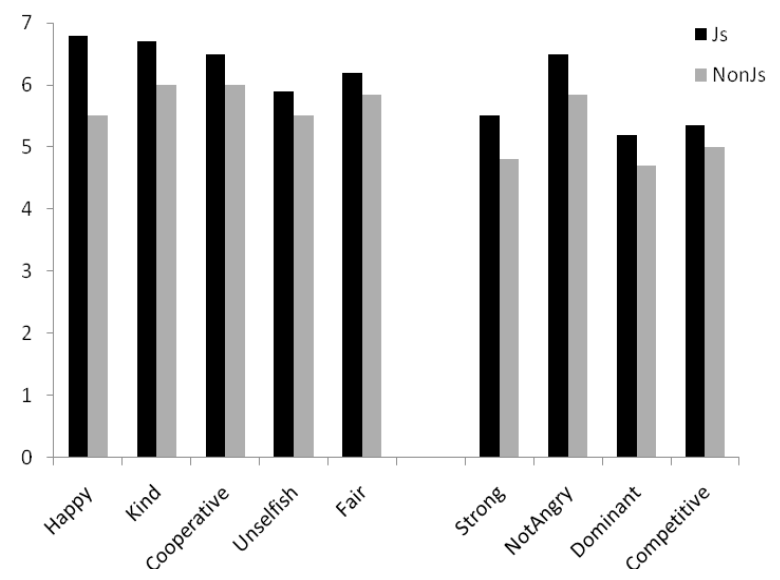

Figure 1. Semantic differential ratings of $\mathrm{J}$ and NonJ targets

more kind, happy, cooperative than males, and less dominant, strong, unfair, angry, and competitive.

\section{Main Effect for SVO}

The global multivariate main effect for SVO was significant, $\mathrm{F}(18,95)=14.95, \mathrm{p}<.00001$. Singledf contrasts showed differences between Js versus NonJs, F $(9,104)=27.84, \mathrm{p}<.00001, \mathrm{~h}^{2}=.71$, and a considerably smaller, but significant effect for Os versus $R_{s}, \mathrm{~F}(9,104)=2.22, \mathrm{p}=.027, \mathrm{~h}^{2}=.16$.

$J_{S}$ versus NonJs. Univariate effects for Js versus NonJs were found for all nine semantic-differential scales, $\mathrm{p}<.0001$. As shown in Figure 1, all were in the expected direction. For the five left-most scales, (the Evaluation, or socially desirable traits), and the four right-most scales (the Dynamism, or personally desirable traits), Js are rated higher than NonJs.

Os versus $R_{s}$. Univariate effects for Os versus $\mathrm{R}_{\mathrm{S}}$ were present for only four traits. Compared to Os, $\mathrm{Rs}$ were rated as more happy $\left(\mathrm{p}=.023, \mathrm{~h}^{2}=.05\right)$, kind $\left(p=.010, h^{2}=.06\right)$, cooperative $\left(p=.029, h^{2}=\right.$ $.04)$, and less angry $\left(\mathrm{p}=.004, \mathrm{~h}^{2}=.07\right)$. The largest $\mathrm{h}^{2}$ for these four scales was less than the smallest $\mathrm{h}^{2}$ for the $\mathrm{J}$ versus NonJ comparisons reported above. Thus the most important distinction among the three SVO groups appears to be the difference between cooperative (Js) and non-cooperative (Os and $\mathrm{R}_{\mathrm{s}}$ ) targets. This is consistent with Shelley et al.'s (2009) findings, and with the practice of most SVO researchers to combine Os and $\mathrm{Rs}_{\mathrm{s}}$ into a single group of non-cooperators.

\section{Discussion}

Our predictions are well supported. Specifically, the differences seen in the "real people" videotapes of $\mathrm{Js}_{\mathrm{s}}$ and NonJs are very consistent with the distinctions made by judges in Teta's masters thesis who were rating hypothetical, idealized J and NonJ personalities. It appears that people possess a-priori' theories regarding numerous traits of cooperative and non-cooperative persons, and also that these theories are correct. Such accuracy

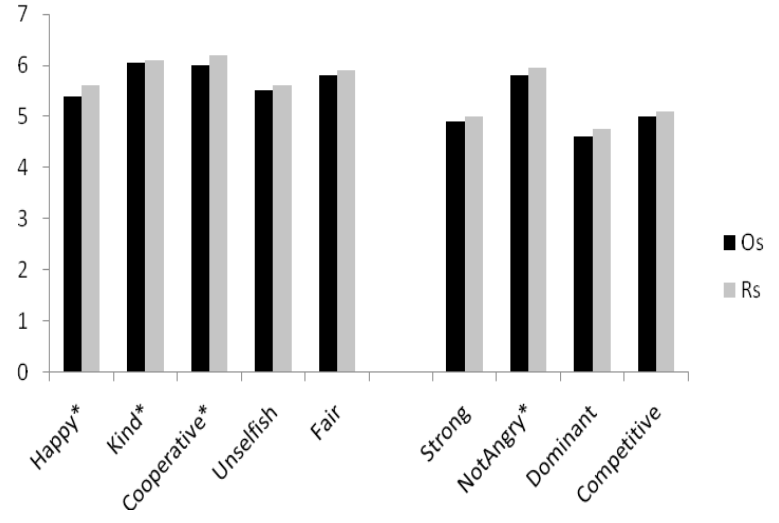

Figure 2. Semantic differential ratings of Os and Rs

Note: Items with an asterisk are significant.

would be possible in a world where cooperative vs. non-cooperative people can be distinguished, which is precisely what the present study and many others concerned with cooperator detection suggest is the case.

Previous research by Liebrand, Jansen, Rijken, and Suhre (1986) demonstrated the "Might Over Morality" effect, which involves a difference between Js and NonJs in their use of Might (Dynamism) and Morality (Evaluation) in distinguishing between cooperative and competitive behavior. For J judges, it is more a matter of Morality, and for NonJ judges it is more a matter of Might. This suggests that in judging the cooperativeness of others, Js and NonJs may be attending to different types of information: Morality cues for Js, and Might cues for NonJs. Nonverbal cues for both dimensions are present in the sort of videotapes used in the present study, and also we assume, in many real-world conversational settings. This could account for the finding that the SVO of the judge played hardly any role in judgmental accuracy in the studies reported by Shelley et al. (2009). Thus, an important issue for future research would be to see if in judging the SVO of strangers, Js are more responsive to nonverbal cues associated with Morality and NonJs to cues associated with Might.

Previous work on cooperator detection, including the results of the present study suggests that Js differ from NonJs in terms of a general aura of positivity. Shelley et al. (2009) show that Js display more "genuine" smiles in casual conversation, and the present study suggests that they look "good" on dimensions of social and personal desirability. That may be only part of the story however. It has been known since Kuhlman and Marshello (1975) that the cooperation of $\mathrm{Js}$ is conditional, in that they follow a Tit-For-Tat (TFT) strategy. They desire, and reciprocate cooperation, but respond to their partner's defection by defecting themselves. Recently Schug, Matsumoto, Horita, Yamagishi, and Bonnett (in press) have shown that cooperators are more emotionally expressive than non-cooperators in re- 
sponding negatively to anti-social actions. Results of the present study combined with Schug et al. (in press) suggest that the nonverbal behavior of cooperators is consistent with Axelrod's (1984) characterization of TFT as both fair and at the same time strong.

\section{Acknowledgement}

This article is based on Greg Shelley's doctoral dissertation entitled Social Orientation and Nonverbal Behavior: A Lens Model Approach to Perceptions of Social Orientation. For a full report of all effects observed in this study, interested readers can email the senior author for a copy of his dissertation.

\section{References}

Axelrod, R. (1984). The evolution of cooperation. New York: Basic Books.

Bem, D. J., \& Lord, C. G. (1979). Template Matching: A proposal for probing the ecological validity of experimental settings in social psychology. Journal of Personality and Social Psychology, 37, 833-846. (doi:10.1037/0022 3514.37.6.833)

Brown, W. M., Palameta, B., \& Moore, C. (2003). Are there nonverbal cues to commitment? An exploratory study using the zero-acquaintance video presentation paradigm. Evolutionary Psychology, 1, $42-69$.

Dawkins, R. (1989). The selfish gene. Oxford: Oxford University Press.

Frank, R. H. (1988). Passions within reason: The strategic role of the emotions. New York: W. W. Norton.

Kuhlman, D. M., \& Marshello, A. F. J. (1975). Individual differences in game motivation as moderators of preprogrammed strategy effects in prisoner's dilemma. Journal of Personality and Social Psychology, 32, 922-931. (doi: 10.1037/0022-3514.32.5.922)

Kuhlman, D. M., \& Wimberley, D. L. (1976). Expectations of choice behavior held by cooperators, competitors and individualists across four classes of experimental games. Journal of Personality and Social Psychology, 34, 69-81. (doi: 10.1037/0022-3514.34.1.69)

Kuhlman, D. M., Camac, C. R., \& Cunha, D.A. (1986). Individual differences in social orientation. In H. Wilke, D. Messick, \& C. Rutte (Eds.), Experimental social dilemmas (pp. 151-176). New York: Verlag Peter Lang.

Liebrand, W. B. G., Jansen, R. W. T. L., Rijken, V. M., \& Suhre, C. J. M. (1986). Might over morality: Social values and the perception of other players in experimental games. Journal of Experimental Social Psychology, 22, 203-215. (doi:10.1016/0022-1031(86)90024-7)

Liebrand, W. B. G., \& McClintock, C. G. (1988). The ring measure of social values: A computerized procedure for assessing individual differences in information processing and social value orientation. European Journal of Personality, 2,
217-230. (doi: 10.1002/per.2410020304)

McClintock, C. G., \& Allison, S. T. (1989). Social value orientation and helping behavior. Journal of Applied Social Psychology, 19, 353-362.(doi: 10.1111/i.1559-1816.1989.tb00060

Messick, D. M., \& McClintock, C. G. (1968). Motivational basis of choice in experimental games. Journal of Experimental Social Psychology, 4, 1-25. (doi:10.1016/0022-1031(68)90046-2)

Osgood, C. E., Suci, G. J., \& Tannenbaum, P. H. (1957). The measurement of meaning. Urbana, IL: University of Illinois Press.

Schug, J., Matsumoto, D., Horita, Y., Yamagishi, T., \& Bonnet, K. (in press). Emotional expressivity as a signal of cooperation. Evolution and Human Behavior. (doi:10.1016, i.evolhumbehav.2009.09.006

Shelley, G. P., Page, M. J., Rives, P., Yeagley, E., \& Kuhlman, D. M. (2009). Nonverbal communication and detection of individual differences in social value orientation. In R. M. Kramer, M. H. Bazerman, \& A. E. Tenbrunsel (Eds.), Social decision making: Social dilemmas, social values, and ethical judgments (pp. 147-169). New York: Psychology Press.

Takahashi, C., Yamagishi, T., Tanida, S., Kiyonari, T., \& Kanazawa, S. (2006). Attractiveness and cooperation in social exchange. Evolutionary Psychology, 4, 315-329.

Van Lange, P. A. M., \& Kuhlman, D. M. (1994). Social value orientations and impressions of partner's honesty and intelligence: A test of the might versus morality effect. Journal of Personality and Social Psychology, 67, 126-141. (doi:10.1037/0022-3514.67.1.126)

Verplaetse, J., Vaneste, S., \& Braeckman, J. (2007). You can judge a book by its cover: The sequel. A kernel of truth in predictive cheating detection. Evolution and Human Behavior, 28, 260-271. (doi:10.1016/j.evolhumbehav.2007.04.006) 